\title{
François Bernier (trad.), Confucius ou la Science des
}

\section{Princes}

Paris, Éditions du Félin, coll. « Les marches du temps », 2015, 389 p., introduction et notes par Sylvie Taussig, note sinologique de Thierry Meynard.

\section{Benoît Vermander}

\section{(2) OpenEdition}

12 Journals

Édition électronique

URL : http://journals.openedition.org/assr/28167

DOI : 10.4000/assr.28167

ISSN : $1777-5825$

Éditeur

Éditions de l'EHESS

\section{Édition imprimée}

Date de publication : 31 décembre 2016

Pagination : 269

ISSN : 0335-5985

\section{Référence électronique}

Benoît Vermander, «François Bernier (trad.), Confucius ou la Science des Princes », Archives de sciences sociales des religions [En ligne], 176 | octobre-décembre 2016, mis en ligne le 17 juillet 2017, consulté le 24 septembre 2020. URL : http://journals.openedition.org/assr/28167 ; DOI : https://doi.org/10.4000/ assr.28167

Ce document a été généré automatiquement le 24 septembre 2020.

(c) Archives de sciences sociales des religions 


\section{François Bernier (trad.), Confucius ou la Science des Princes}

Paris, Éditions du Félin, coll. « Les marches du temps », 2015, 389 p., introduction et notes par Sylvie Taussig, note sinologique de Thierry Meynard.

\section{Benoît Vermander}

\section{RÉFÉRENCE}

François Bernier (trad.), Confucius ou la Science des Princes, Paris, Éditions du Félin, coll. « Les marches du temps », 2015, 389 p., introduction et notes par Sylvie Taussig, note sinologique de Thierry Meynard.

1 En 1687, paraissait à Paris le Confucius Sinarum philosophus (CSP), une traduction latine de trois des Quatre Livres confucéens (le Mencius n'avait pas été inclus). Pour réaliser leur entreprise, les jésuites Philippe Couplet, Christian Herdtrich, Prosper Intorcetta et François de Rougemont s'étaient appuyés sur une histoire déjà presque centenaire de traductions missionnaires, la plupart alors non publiées. Outre les notes et introductions des traducteurs, l'ouvrage offrait, en latin et en chinois, le texte original accompagné d'une sélection des Commentaires qui traditionnellement encadraient l'interprétation des Classiques. Cette présentation systématique de l'orthodoxie confucéenne allait influencer profondément la pensée européenne. Très vite apparaissent des adaptations ou traductions partielles de l'ouvrage, en français et autres langues. Les deux premières, dues à Simon Fouchet et Louis Cousin, apparaissaient l'année suivant la publication de l'ouvrage.

Conservée à la bibliothèque de l'Arsenal, la traduction française du CSP ici publiée était jusque là restée inédite : François Bernier, son auteur, avait traduit le texte latin dès 1687, et mourait en 1688. Bernier, disciple et vulgarisateur de Gassendi, avait passé treize ans en Orient, dont huit dans l'Inde moghole. Sa traduction du CSP en est aussi une appropriation : il traduit essentiellement le texte latin des Trois Livres, intégrant 
néanmoins des extraits des commentateurs chinois ou des notices des éditeurs lorsque ces ajouts lui semblent nécessaires à la compréhension du texte. Ainsi, dans sa traduction du fragment X.25 des Analectes, plutôt que de seulement noter, comme le voudrait le texte, que Confucius changeait de couleur lors d'un orage soudain ou d'une bourrasque violente, il garde cette fois le commentaire de Zhang Juzheng, ajoutant : « Comme un homme qui est touché d'une horreur sacrée et qui témoigne la révérence qu'il a pour la souveraine Majesté du Ciel» (p. 291). Par ailleurs, le Daxue (La Grande Étude) et le Zhongyong (La Doctrine du Milieu) sont fortement réorganisés, alors que sa traduction du Lunyu (Analectes) est presque linéaire. La langue de Bernier est plaisante, parfois même savoureuse. Il sait «acculturer» le texte avec bonheur. Ainsi, l'on voit Confucius se courber profondément «toutes les fois qu'il se trouvoit à la porte Royale du Louvre» (p. 285 - néanmoins, pareilles re-créations restent rares).

La longue introduction de Sylvie Taussig est riche en indications sur le contexte intellectuel et politique de cette étape des échanges entre l'Europe et la Chine. Elle aurait gagné à être plus clairement organisée (pas un intertitre pour environ cent pages de texte). Mais elle dégage avec bonheur la portée proprement politique du texte, que le titre annonce déjà. L'accent porte moins sur le caractère universel de la morale chinoise, comme c'était le cas chez La Mothe Le Vayer (De la vertu des payens, 1642) que sur la capacité des Classiques chinois à former les princes au gouvernement (p. 90-91). La courte « Note » de Thierry Meynard (auteur d'une édition et traduction partielle en anglais du CSP) dégage les caractéristiques principales de l'ouvrage : une traduction du texte latin de facture très sûre, l'omission de l'immense majorité des notes historiques composées par les jésuites, et une réduction de la complexité herméneutique des textes présentés, complexité que le CSP avait su faire entrevoir.

4 Si le texte de Bernier, resté inédit, n'a pu jouer un rôle dans l'histoire de la pensée, sa publication n'en est pas moins heureuse. Elle peut faciliter la consultation directe du CSP et éclairer la compréhension qu'en avaient les contemporains. Et la langue de Bernier permet parfois de réentendre les propos de Confucius comme à neuf. Qu'on en juge par la manière dont le fragment II.12 des Analectes est rendu: "L'homme parfait n'est point un vase, plus il est parfait, plus il est capable de perfection, plus il doit songer à se perfectionner. Ce n'est point un instrument qui soit borné et limité à un certain usage; mais comme il est donc de grands et divers talents, il est propre à faire de grandes et diverses choses » (p. 238). 